VOL 4 (2020) NO 2

e-ISSN : 2549-9904

ISSN : 2549-9610

INTERNATIONAL JOURNAL ON INFORMATICS VISUALIZATION

\title{
M-Learning: Positioning the Academics to the Smart devices in the Connected Future
}

\author{
Tanweer Alam, Mohammed Aljohani ${ }^{\#}$ \\ \# Faculty of Computer and Information Systems, Islamic University of Madinah, Saudi Arabia \\ E-mail: tanweer03@iu.edu.sa
}

\begin{abstract}
M-learning is about using the massive growth of mobile technologies to benefit learners and learning. As computers and the internet become essential educational tools, the technologies become more portable, affordable, effective and easy to use. Using portable computing devices (such as laptops, tablet PCs, PDAs, and smartphones) with wireless networks enables mobility and mobile learning, allowing college teaching and learning to extend to spaces beyond the traditional classroom. Within the classroom, mobile learning gives university instructors and learners increased flexibility and new opportunities for interaction. Decision support systems can play an important role in decision making for the interaction of instructors and students. Mobile technologies can support learning experiences at the university level that are collaborative, accessible, and integrated with the world beyond the classroom educative learning initiative. In the proposed framework we will use a decision support system for taking some decisions using the system. The system will notify students when they need alert of lecture time, low attendance, meeting time, exam schedule notification, result etc. Also, the Framework will take quizzes periodically for improving the quality of learning of each class and send the result to the student as well as faculty and add this result in the record of the student in university. Students can ask general and technical questions from the system, system reply answer of general questions and send technical questions to the faculty, faculty reply through the system. The student also votes at the end of every lecture, if the system found against vote then send the message to the concerned faculty for improvement in the lecture. My research will be more helpful for students and university teachers to increase flexibility and interaction with students more effectively.
\end{abstract}

Keywords - M-learning, Mobile Technologies, Teaching Instructors, Decision Support System, University.

\section{INTRODUCTION}

Now-a-days, in whole world the smart mobile phone users are increasing exponentially because smart mobiles provide most user friendly platform [1]. So people adopt this technology very well. Smart phones provide more facility to the end users and also attach with their daily life. In the starting of mobile device, it is simple mobile with calling and SMS facilities. They enhance mobile phone technology and add facilities to the generation of mobiles. Now normal mobile is converted into smart phone. The smart phone has advance features more than normal phone. It provides more efficient applications; those applications make life of peoples more comfortable. Smart phones provide applications for using many facilities like access web browser, watch Live TV, take photo or make video by camera, listen music or FM etc. In recent years Mobile learning has obtained a lot of awareness as a growing section of the educational and instructional technology field. In m-learning users can access to learning resources independent of time and location. In this research we describes an approach to an intelligent DSS design framework for m-learning and use intended to enhance the development of both general and specific problem-solving skills of the user by encouraging the use m-learning technology as a tool for learning. Every university can easily implement this research for their students and staffs without huge infrastructure.

M-Learning or Mobile Learning is one of the ability that provides the learning material for the students and teachers on mobile devices. Now a day Smartphone makes the life of people easy and most important part of people's daily life. In the whole world, the mobile based technology is become the part of the lives of peoples. Because people can talk or chat to other peoples at anytime from anywhere using mobile phones. Also we can access the location, information, images, record voice with one device, and that we can share these with our friends, colleagues or the wider world [2]. The growth of mobile based technology has been experienced unprecedented in the variety and capabilities of mobile devices and in the number of people using them. Technology is not only changing the way the world operates; it's changing the way we learn, and the way we offer learning. Educational institutions are facing the challenge of providing students with tools for mobile learning. However, the evolution of 
technology makes the development and continuous impro $\neg$ vement of these tools rather expensive. In this research, we propose a mobile information system framework using decision support system for mobile learning in order to develop application for designing, implementing, evaluating and development of mobile learning [3].

\section{Previous Studies}

Learning is a continuous process that does not stop when a student leaves the formal school setting. The learning experiences will continue, especially with the emergence of high access to mobile technologies and devices that are being used for many educational and communicative purposes. Many researchers have discussed how outside-the-classroom learning activities such as experiments, unintentional discoveries, events and various experiences can be classified as informal learning.

In 2003, Robby Robson publish a research paper on "Mobile Learning and Handheld Devices in the Classroom", in this paper he propose a new m-learning architecture that support creation, brokerage, delivery and tracking of learning and information contents, using ambient intelligence, locationdependence, personalization, multimedia, instant messaging (text,video) and distributed databases [4].

In 2008, Jan Herrington, Jessica Mantei, Anthony Herrington, Ian Olney and Brian Ferry, write one paper on "New technologies, new pedagogies: Mobile technologies and new ways of teaching and learning", In this paper describes a major development and research study that investigated the use of mobile technologies in higher education. The project investigated the educational potential of two ubiquitous mobile devices: Palm smart phones and iPod digital audio players (mp3 players). An action learning framework for professional development was designed and implemented with a group of teachers from a Faculty of Education. Each teacher or team created pedagogies to implement appropriate use of a mobile device in different subject areas in higher education [5].

In 2010, Karen Melhuish, publish a research paper on "Looking to the future: M-learning with the iPad", in this paper explores the potential affordances and limitations of the Apple iPad in the wider context of emergent mobile learning theory, and the social and economic drivers that fuel technology development. Against the background of effective teaching and learning, the functionality offered by the iPad, and its potential uses for learning, are discussed [6].

Currently the Advanced Distributed Learning (ADL) initiative is leading a project that will develop an instructional design framework with best practices and design guidelines to better support mobile learning design (ADL, 2012). The OECD and UNESCO have also initiated projects and published reports on mobile learning. For example, UNESCO has recently published a working paper series on mobile learning to provide examples of global initiatives in mobile learning and also policy guidelines for implementation.

\section{METHODOLOGIES}

M-learning is convenient, in the sense that it is accessible virtually from anywhere (class, taxi, laundry room, bathroom etc.) which provides access to all the different learning materials available. Moreover, it is collaborative; that is sharing is almost instantly among everyone using the same content, which will in turn also lead to receiving instant feedback and tips. M-Learning also brings strong portability by replacing books and notes with small RAM [7]. In addition, this kind of learning is engaging and fun. With this kind of learning, it is much easier to combine gaming and learning for a more effective and entertaining experience. Mobile devices engage learners - young people who may have lost interest in education - like mobile phones, gadgets and games devices such as Nintendo DS or Play station Portable [8], [9], [10].

The following are objectives of our research.

1. To enable students to communicate and share ideas effectively in University [11].

2. To support differentiation of student learning needs and personalized learning.

3. To enable new developments in formative and summative assessment [12].

4. To increase motivation and address low interaction levels in large classes.

5. To improve retention and achievement, by improved monitoring of student attendance and by giving immediate and regular feedback to students regarding attendance and progress - teachers were able to do this by having ready access to information on their mobile devices [13].

6. Making wireless, mobile, interactive learning available to all students without incurring the expense of costly hardware.

7. Delivering communications, information and training to large numbers of people regardless of their location.

8. Blending mobile technologies into e-learning infrastructures to improve interactivity and connectivity for the learner.

Mobile handheld devices are increasingly being used in education. In the last few years, mobile handheld devices have emerged as a tool for teachers and students to use in K-12 and higher education settings.[14], [15]. Mobile phones started as voice communication tools; however, they rapidly become devices for text and image exchange, and recent models include built in cameras [16]. Various research methods used in the previous studies we reviewed. A total of eight types of research methods were found: descriptive research, true experiment, experiment (weak), quasi-experiment, ex-post facto, single-subject, design-based research, and mixed method. The data collection methods that were found in our review of past empirical studies included the following five methods: test or quiz, questionnaire, interview or focus group discussion, observation, and content analysis. There are several methodological limitations concerning previous empirical studies. First, a majority of studies used a weak experimental method that utilised a one group pretest and posttest design to examine student learning outcomes due to use of mobile handheld devices use.

According to [17], without a control group, differences found between pretest and posttest scores might not necessarily be attributable to the use of mobile handheld devices such as a PDA or mobile phone. Adding a control group and random assignment of participants to the research design could strengthen a study considerably [17]. While this may be true, we are hesitant to advocate media comparison 
studies per se (e.g., one group with PDA versus one group without PDA). This is because historically researchers in instructional technology have voiced concerns about comparing learning outcomes between different media due to the presence of many potential confounding variables which makes the task of pinpointing a specific factor or factors that may account for the learning difference difficult, if not impossible [18]. Instead, since different media possess different attributes [19], future research studies might focus on investigating where and how to best use mobile devices as an instructional medium.

\section{DISCUSSION}

In the scientific literature of mobile authoring, the authors of [20] propose an authoring tool named Mobile E-learning Authoring Tool (MEAT) to produce adaptable learning contents and test items. In addition, the visualized course organization tool has also been provided to teachers to organize their courses. All functionalities of the MEAT are designed according to the teachers' feedback and their technological learning needs. To evaluate the MEAT, the authors have conducted an extensive comparison between the MEAT and other (adaptation) content authoring tools. The results indicate that MEAT can produce adaptable contents and test items while supporting learning standard.

Moving on more recent works considering mobile learning, in [21] the authors designed a portable multiple-channel message servicing technology for educational reasons where the responding speed and service quality were greatly improved.

The research presented in [22] examines the factors affecting social acceptability of multimodal interactions, beginning with gesture-based interfaces. The results of this study revealed the importance of social acceptability, demonstrating that some gestures were significantly more accepted than others.

\section{CONCLUSION}

M-Learning or Mobile Learning is one of the ability that provides the learning material for the students and teachers on mobile devices. Now a day Smartphone makes the life of people easy and most important part of people's daily life. In the whole world, the mobile based technology is become the part of the lives of peoples. The use of mobile technologies to support, enhance and improve access to learning is a relatively new idea and while many teenagers and twenty plus are expert mobile phone users many educators are not. Decision support systems can play an important role for decision making for interaction of instructors and students. Mobile technologies can support learning experiences at the university level that are collaborative, accessible, and integrated with the world beyond the classroom educative learning initiative. In this research we will design a framework by using decision support system in mobile learning for universities. My research will be more helpful for students and university teachers to increase flexibility and interaction with students more effectively.

\section{REFERENCES}

[1] Georgiev, Tsvetozar, Evgenia Georgieva, and Angel Smrikarov. "Mlearning-a New Stage of E-Learning." In International conference on computer systems and technologies-CompSysTech, vol. 4, no. 28, pp. 1-4. 2004.

[2] Peters, Kristine. "m-Learning: Positioning educators for a mobile, connected future." The International Review of Research in Open and Distributed Learning 8, no. 2 (2007).

[3] Navarro, Christian X., Ana I. Molina, Miguel A. Redondo, and Reyes Juárez-Ramírez. "Framework to evaluate m-learning systems: A technological and pedagogical approach." IEEE Revista Iberoamericana de Tecnologias del Aprendizaje 11, no. 1 (2016): 33-40

[4] obby Robson 2003 Mobile Learning and Handheld Devices in the Classroom.Eduworks Corporation.Corvallis (Oregon:USA) Jan Herrington, Jessica Mantei, Anthony

[5] Herrington, Ian Olney and Brian Ferry, New technologies, new pedagogies: Mobile technologies and new ways of teaching and learning, Proceedings ascilite Melbourne, 2008

[6] Melhuish, Karen, and Garry Falloon. "Looking to the future: Mlearning with the iPad." (2010): 1-16.

[7] Tanweer Alam, "Middleware implementation in MANET of Android Devices", International Journal of Electronics and Information Engineering, Vol. 12(2), 2020.

[8] Tanweer Alam and Mohammed Aljohani, "Decision Support System for Real-Time People Counting in a Crowded Environment", International Journal of Electronics and Information Engineering, Vol. 12(1), 2020

[9] Tanweer Alam, "Internet of Things: A Secure Cloud-Based MANET Mobility Model", International Journal of Network Security, Vol. 22(3), 2020 .

[10] Tanweer Alam, Yazeed Mohammed Alharbi, Firas Adel Abusallama, Ahmad Osama Hakeem, "Smart Campus Mobile Application Toward the Development of Smart Cities", International Journal of Applied Sciences and Smart Technologies, Vol. 2 (1), 2020.

[11] Tanweer Alam, "A Middleware Framework between Mobility and IoT Using IEEE 802.15.4e Sensor Networks", Jurnal Online Informatika, Vol 4, No 2 (2019). DOI: https://doi.org/10.15575/join.v4i2.487

[12] Alam, T. Cloud Computing and Its Role in the Information Technology. IAIC Transactions on Sustainable Digital Innovation (ITSDI) 2020, 1, 108-115. DOI: https://doi.org/10.34306/itsdi.v1i2.103

[13] Alam, Tanweer, and Mohammed Aljohani. "Design and implementation of an Ad Hoc Network among Android smart devices." In Green Computing and Internet of Things (ICGCIoT), 2015 International Conference on, pp. 1322-1327. IEEE, 2015. DOI: https://doi.org/10.1109/ICGCIoT.2015.7380671

[14] Alam, Tanweer, and Mohammed Aljohani. "An approach to secure communication in mobile ad-hoc networks of Android devices." In 2015 International Conference on Intelligent Informatics and Biomedical Sciences (ICIIBMS), pp. 371-375. IEEE, 2015. DOI: https://doi.org/10.1109/iciibms.2015.7439466

[15] M. Aljohani and T. Alam, "Design an M-learning framework for smart learning in ad hoc network of Android devices," 2015 IEEE International Conference on Computational Intelligence and Computing Research (ICCIC), Madurai, 2015, pp. 1- 5. DOI: https://doi.org/10.1109/ICCIC.2015.7435817

[16] Oliver, Beverley, and Veronica Goerke. "Australian undergraduates' use and ownership of emerging technologies: Implications and opportunities for creating engaging learning experiences for the Net Generation." Australasian Journal of Educational Technology 23, no. 2 (2007).

[17] Tallent-Runnels, Mary K., Julie A. Thomas, William Y. Lan, Sandi Cooper, Terence C. Ahern, Shana M. Shaw, and Xiaoming Liu. "Teaching courses online: A review of the research." Review of educational research 76, no. 1 (2006): 93-135.

[18] Clark, Richard E. "When researchers swim upstream: Reflections on an unpopular argument about learning from media." Educational Technology 31, no. 2 (1991): 34-40.

[19] Kozma, Robert B. "Will media influence learning? Reframing the debate." Educational technology research and development 42, no. 2 (1994): 7-19.

[20] Kuo, Yen-Hung, and Yueh-Min Huang. "MEAT: An authoring tool for generating adaptable learning resources." Educational Technology \& Society 12 , no. 2 (2009): 51-68. 
[21] Zhan, Hong-fei, and Hui-jun Deng. "Study on a Portable Education Administration Assistant System." In 2010 International Conference on Communications and Mobile Computing, vol. 1, pp. 555-558. IEEE, 2010 .
[22] Rico, Julie. "Evaluating the social acceptability of multimodal mobile interactions." In CHI'10 Extended Abstracts on Human Factors in Computing Systems, pp. 2887-2890. 2010. 